\title{
Estrategias de negocios ante la crisis sanitaria: el caso de Perú
}

Bussines strategies in the face of the heath crisis: peru case

Estratégias empresariais frente a crise da saúde: o caso do Peru

\author{
Felipe Rafael Valle Díaz \\ fvalle@unajma.edu.pe \\ https://orcid.org/0000-0003-0855-9688 \\ Universidad Nacional José María Arguedas-Perú
}

\begin{abstract}
RESUMEN
El objetivo de la investigación fue: dar a conocer la diversidad de estrategias de negocios para enfrentar la crisis sanitaria: caso Perú. La investigación pertenece al enfoque cualitativo, de tipo básica, diseño no experimental, ligado al estudio de caso. Las técnicas de investigación fueron: análisis de documentos. Las unidades de análisis fueron los hechos que atravesaron las empresas producto de las medidas de prevención y aislamiento contra la propagación del Covid-19, detallados en fuentes secundarias. Conclusión: Las estrategias a implementar para sobrevivir, readaptarse, e iniciar una mejora, es planificar bajo tres escenarios posibles de recuperación: lento, medio, y rápido; diagnosticar caja chica, las cuentas por cobrar y compromisos con proveedores pendientes, renegociar las deudas de corto plazo ante la escasez de capital de trabajo, tomar decisión en la reducción de costos en áreas y procesos que no son imprescindibles, reorientar el gasto operativo hacia responder para mantener la continuidad del negocio, ceñido a la implementación de tecnología y plataformas digitales, cuyo rol es determinante; sumado a aprender a surgir más fuerte, idear soluciones proactivas; aprovechar los aprendizajes de la crisis actual, que permita sobreponerse sin mucha dificultad, lo cual demuestra la capacidad de la empresa para cambiar la trayectoria, agregar valor, lograr que el negocio escale.
\end{abstract}

Palavras-chave: estrategia de negocio, covid-19, aislamiento social.

\section{RESUMO}

O objetivo da pesquisa foi: divulgar a diversidade de estratégias empresariais para enfrentar a crise da saúde: o caso do Peru. A pesquisa pertence à abordagem qualitativa, de tipo básico, de delineamento não experimental, vinculada ao estudo de caso. As técnicas de pesquisa foram: análise documental. As unidades de análise foram os eventos pelos quais as empresas passaram em decorrência das medidas de prevenção e isolamento contra a disseminação da Covid-19, detalhadas em fontes secundárias. Conclusão: as estratégias que você deve implementar para sobreviver, reajustar e iniciar uma melhoria são planejar sob três cenários de recuperação possíveis: lento, médio e rápido; diagnosticar caixa pequeno, contas a receber e compromissos com fornecedores pendentes, renegociar dívidas de curto prazo por falta de capital de giro, tomar decisões para reduzir custos em áreas e processos que não são essenciais, redirecionar despesas operacionais para responder manter a continuidade do negócio, limitada à implementação de tecnologia e plataformas digitais, cujo papel é decisivo; adicionado ao aprendizado de emergir mais forte, conceber soluções proativas; aproveitar as lições aprendidas com a crise atual, permitindo que ela seja superada sem muitas dificuldades, o que mostra a capacidade da empresa de mudar a trajetória, agregar valor e ampliar a escala do negócio.

Palavras-chave: estratégia empresarial, covid-19, isolamento social.

\begin{abstract}
The objective of the research was: to publicize the diversity of business strategies to face the health crisis: the case of Peru. The research belongs to the qualitative approach, of a basic type, non-experimental design, linked to the case study. The research techniques were: document analysis. The units of analysis were the events that the companies went through as a result of the prevention and isolation measures against the spread of Covid-19, detailed in secondary sources. Conclusion: The strategies to must implement to survive, readjust, and start an improvement, is to plan under three possible recovery scenarios: slow, medium, and fast; diagnose petty cash, accounts receivable and commitments with pending suppliers, renegotiate short-term debts due to the shortage of working capital, make a decision to reduce costs in areas and processes that are not essential, redirect operating expenses towards responding to maintain business continuity, limited to the implementation of technology and digital platforms, whose role is decisive; added to learning to emerge stronger, devise proactive solutions; Take advantage of the lessons learned from the current crisis, allowing it to be overcome without much difficulty, which shows the company's ability to change the trajectory, add value, and make the business scale.
\end{abstract}

Keywords: bussines strategy, covid-19, social isolation. 


\section{INTRODUCCIÓN}

Desde inicios de marzo del 2020, según OMT (2020) señala que, a nivel mundial, nacional, se han sufrido pérdidas económicas, en empresas; según su tamaño de infraestructura, por cantidad de trabajadores; por constitución en micro a mediana y grande; esta situación que atravesamos hoy a enero 2021, es difícil de superar, por el motivo de que prosiguen los contagios y que la intervención estatal no es suficiente. A partir de lo comunicado por el MINSA (2020) la adopción de las medidas de aislamiento y confinamiento social, además de los tratamientos individuales, y familiares, para frenar la propagación del Covid-19, durante los últimos 8 meses, se determinó que el virus presentó un periodo de incubación entre un periodo de 7 a 10 días, cuyos síntomas y detección dependía de la condición física, biológica, psicológica, espiritual de cualquier individuo, presentando cuadros de contagios diversos, pero con síntomas similares; por ello se tuvo que promulgar la ampliación de las medidas de cuarentena, para frenar los contagios progresivos y el colapso total del sistema de salud, lo cual repercute también a la economía.

A diciembre del 2020, señalado por el MINSA (2020) se generó los rebrotes de la pandemia Covid-19, que se identificó como segunda ola; a diferencia de la anterior, es más agresiva porque el periodo de incubación de infección, es entre 3 a 7 días, a partir de lo expuesto por el MINSA (2020) a través de los boletines informativos en diversos medios de comunicación, el virus es mortal en extremo; e inclusive el grupo frecuente de fallecidos fueron adultos mayores, ahora se expande a adultos menores de 60 años.

La realidad del sector empresarial peruano, según diario Gestión, (2020), en columna de opinión precisa que la conversión tecnológica es una alternativa imperante, según el INEI (2020) manifiesta que "entre julio a septiembre 2020, se constituyeron mas de 78 mil empresas y se dieron de baja mas de 5 mil" (p. 2). Además el INEI (2020) indica que, las actividades que presentaron un mayor número de bajas en el mismo trimestre fueron; comercio al por menor con $34.8 \%$, comercio por mayor $16.0 \%$, otros servicios el $11.7 \%$, transportes y almacenamiento con $8.7 \%$, servicios de comidas y bebidas el $7.8 \%$, siendo las mas representativas (p. 5) Asimismo, a partir del reporte del INEI (2020) "las organizaciones jurídicas con mayor número de bajas son las personas naturales con el 98.4\%, asimismo para las empresas individuales de responsabilidad limitada con $23.0 \%$ y sociedada comercial de responsabilidad limitada con $3.7 \%$ " (p. 8 ) .

Es necesario recordar que por encima del $87 \%$ a nivel nacional, el tejido empresarial son microempresas, el restante se divide entre pequeña, mediana y grande empresa. La forma de operar difiere, según el grado de intensificación tecnológica e inversión en ampliación, renovación del negocio. Sumado que gracias al avance de la pandemia Covid-19, se logró evidenciar y confirmar que la informalidad de la economía peruana alcanza un 69\%. Dado el contexto, situación que se atraviesa, el sector empresarial, se formuló la siguiente pregunta que direcciona la investigación: ¿Cuáles serán las estrategias de negocio para enfrentar la crisis sanitaria: caso Perú? La interrogante general encadenó hacia el objetivo general siguiente: Dar a conocer la diversidad de estrategias de negocios para enfrentar la crisis sanitaria: caso Perú.

\section{MARCO TEÓRICO, PROPUESTA ESTRATÉGICA}

\subsection{Fundamentación teórica y estadística}

Iniciaremos el análisis sobre efectos, experiencias, emergencia y reactivación frente al Covid-19, con literatura especializada y estadísticas. Para Latinoamérica, según CEPAL (2020) "la crisis económica generada por el virus Covid-19, golpea la estructura productiva y empresarial con debilidades que se han originado a lo largo de décadas" (p. 1)

En este sentido CEPAL (2020) manifestó que la estructura productiva es heterogénea, existen pocas actividades de producción y procesamiento de recursos naturales, algunos servicios con alta intensidad de 
capital como electricidad, comunicaciones, bancos; el valor agregado a nivel empresarial micro a mediano, es pobre por trabajador, baja productividad, sujeto además de brechas internas y externas de productividad (p. 1). Además, precisó que entre 1999 al 2018, la productividad de la región alcanzó un quinto de los Estados Unidos, creció $0.6 \%$ en el periodo indicado, sumado a las diferencias de desempeño entre los distintos segmentos de MIPYMES, centrado en la inexistencia de incentivos para el desarrollo de actividades de mayor valor agregado, la alta informalidad prevalece en mercados laborales que alcanza el 54\% (p. 2).

De la misma manera la CEPAL (2020) indicó que la intensidad y duración de la crisis, es difícil prever, ello significa reducción de contactos sociales, lo cual limita las actividades económicas; estas restricciones sociales han generado la suspensión, total o parcial de las actividades productivas, fue notorio, fuerte en sectores cuyas actividades implican aglomeración y cercanía física como: turismo, espectáculos, hoteles, restaurantes, transporte, servicios personales, entre otros; esta interrupción también trajo la paralización de actividades como la provisión de insumos, nacionales y extranjeros, para que las empresas puedan seguir operando (p. 3). A partir de lo expuesto, CEPAL concluyó que la caída de los ingresos, restringe la toma de decisiones de compra en los consumidores y la incertidumbre sirvió para la contracción del consumo y el cambio de patrones de consumo, por ejemplo, cayó las adquisiciones de bienes duraderos como automóviles, muebles, electrodomésticos, viviendas, prendas y calzado; asimismo, a nivel internacional, la fuerte caída del precio del petróleo, generó la reducción generalizada de la demanda externa y de los retornos de las exportaciones (p. 4).

Ahora se aborda escenarios para el bloque Latinoamericano, CEPAL (2020) estima que cerrarían más de 2,5 millones de empresas, siendo el mayor impacto en el caso de micro y pequeñas empresas, cuyas pérdidas ascenderían en 8,5 millones de puestos de trabajo, además que el impacto se acentúa con mayor intensidad en sectores de mayor incidencia de relaciones sociales, como turismo, recreación y ocio (p. 6). A julio 2020, un escenario implementado expuesto por la CEPAL (2020) está referido a que los gobiernos en Latinoamérica, incidieron aprobar e implementar políticas respecto a proveer liquidez y mejorar el acceso a crédito, suman 24 y 22 países respectivamente; en menor intensidad protección del empleo y el apoyo a la producción, suman 18 y 12 países respectivamente (p. 9). La toma decisiones de implementar el rescate, se hizo posible, "a la disposición de fondos públicos como garantía para los créditos que ha sido una de las modalidades más extendidas" (p. 10) en casi todos los países latinoamericanos, que anunciaron líneas de crédito especiales para financiar el capital de trabajo de las MIPYMES, de tal forma que continuarán sus actividades y pagaran sus nóminas; las medidas de crédito anunciadas en la mayoría de países supera el $4 \%$ del Producto Bruto Interno.

A nivel de Perú, las fases de reactivación económica, tuvieron retrasos, limitaciones; sujetas al comportamiento de la propagación y mortandad de la población, frente a la presencia del Covid-19; en otras palabras, estamos vulnerables a la pandemia Covid-19. Según MEF (2020) comparando el primer y segundo trimestre de los años 2019 y 2020, se comprobó que la economía peruana cayó 39\% en promedio, luego al tercer trimestre comparado los mismos años, la economía peruana, cayó 24\%; esto nos demuestra que estábamos entrando a un ciclo de recesión económica, la cual fue atenuada con una serie de medidas económicas; conocido como rescate económico.

Según lo publicado en el diario oficial, El Peruano (2020) señaló que las MYPIMES, desempeñan un papel central en el desarrollo de la economía nacional, constituyen el 99\% de las unidades empresariales, las cuales crean alrededor del $85 \%$ del total de puestos de trabajo y generan aproximadamente el $40 \%$ del Producto Bruto Interno. Por tal motivo, dada la presencia y conformación del empresariado nacional, el gobierno de turno junto al Ministerio de Economía y Finanzas, diseñaron, aprobaron medidas económicas a través de programas para apoyar a las MIPYMES.

Asimismo, según el diario oficial El Peruano (2020) señaló que a través de los Programas Reactiva Perú y el Fondo de Apoyo Empresarial FAE, sumado a que la Superintendencia de Banca y Seguros del Perú, se 
flexibilizó el tratamiento de las provisiones que se aplican a los créditos que otorguen a empresas calificadas, acreditadas, lo cual generó holgura para la colocación de créditos en MIPYMES.

Sin embargo, según INEI (2020) a través de la encuesta de opinión sobre el impacto del Covid-19 en las empresas, nos indicó que: para el periodo de julio - agosto 2020, las empresas en Lima Metropolitana, por estado de operatividad se encontraban el 75.5\%, el restante inoperativas (p. 2) además estas, según INEI (2020) las empresas tuvieron un nuevo comportamiento de sus ventas; indicando que disminuyeron el $67.4 \%$, aumentaron el $7.2 \%$, se mantuvieron el $13.7 \%$ y no realizaron ventas el $11.7 \%$; sumado que, adoptaron una modalidad de ventas, siendo preferentes por vía on line el $25.3 \%$, combinar delivery presencial el $25.8 \%$, solo delivery el $14.4 \%$ y la resistencia en lo presencial el $24.5 \%$ (p. 3, 4). En ese sentido manifiesta otro problema, respecto a la pregunta: si enfrentaron algún problema que vulneró la operatividad, el $92.5 \%$ respondió que sí; asimismo, la mayoría indicó que disminuyó la demanda el $76.9 \%$, tuvo que asumir altos costos en seguridad sanitaria el 58.9\%, el retraso en el cobro de facturas el 52.8\%, la paralización de la producción el 50.4\%, la pérdida de capital de trabajo el $45.0 \%$, el desabastecimiento de materias primas e insumos el 37.3\%, los contagios de trabajadores por el covid-19 el 19.4\%, y la dificultad en la exportación de sus productos el $9.7 \%$ (p. 5)

Asimismo, según INEI (2020) la modalidad de trabajo asumida por las MIPYMES para enfrentar la crisis, fue reducir el trabajo presencial en el rango del 11.3\% al 50.1\%, (para las micro es el límite del intervalo superior) formalizar el trabajo remoto en el rango $25.4 \%$ al $35.6 \%$ (para las micro es el límite inferior) fortalecer el trabajo mixto en el rango del $24.5 \%$ al $60.9 \%$ (para las micro es el límite inferior), las empresas grandes, la principal modalidad fue la mixta con el 65.7\% (p. 6). Además, INEI (2020) manifestó respecto a la medidas laborales adoptada por el empresario, frente al covid-19, aquellas en operación, el 77.5\% adoptó alguna medida laboral; flexibilizaron los horarios el $68.5 \%$, redujo las horas de trabajo el $54.8 \%$, adelantaron vacaciones el $22.5 \%$, entregó un subsidio a la planilla el $22.0 \%$, redujo las remuneraciones el $20.4 \%$, no renovó contratos el $16.0 \%$, otorgó licencia sin goce de haber el $9.0 \%$, aplicó suspensión perfecta de labores el $8.1 \%$, entregó bono extra por trabajo presencial el 2.8\% y resolución de contratos el $1.5 \%$ (p. 7 )

Respecto a la pregunta, si presentaron problemas financieros; según el INEI (2020), debido al impacto del covid-19, en las empresas operativas el $81.4 \%$ pasó por problemas financieros; generado por la dificultad para cobrar a clientes el $53.8 \%$, la falta de liquidez para comprar materias primas y/o insumos el $49.2 \%$, las limitaciones para acceder a fuentes financieras el $46.9 \%$, la falta de liquidez para pagar a proveedores el $46.5 \%$, falta de liquidez para pagar remuneraciones el $43.8 \%$, la dificultad para pagar préstamos al sistema financiero el $37.2 \%$ y la dificultad en la accesibilidad a créditos de proveedores el $33.0 \%$ (p. 8)

Lo importante de las empresas operativas, según INEI (2020) es que van a procurar acceder a un programa de apoyo o medidas de incentivos para ayudar a la reactivación económica, que serían implementadas por el gobierno de turno, el 57.7\% indicó que accedería al menos a un programa; prefieren Reactiva Perú el 78.4\%, a mayores plazos de pago de deuda tributaria el $37.6 \%$, el aplazamiento y/o fraccionamiento de deudas tributarias el $20.5 \%$, la suspensión de pagos del impuesto a la renta el $20.1 \%$, la ampliación de plazos para pérdidas tributarias el $15.5 \%$, Programa FAE el $11.4 \%$, al régimen especial de depreciación el $9.9 \%$, Programa Arranca Perú 7.6\%, otros 7.3\% (p. 9). Un indicador preocupante sobre las empresas operativas, es que muchas no accedieron y no piensan acceder a los programas o medidas de incentivo por diversas razones implementadas por el gobierno, siendo estos el $42.3 \%$; por lo cual, el $35.9 \%$ es por los trámites y/o requisitos excesivos, no tienen conocimiento el $27.1 \%$, no necesita/no requiere el $23.5 \%$, no sabe cómo acceder el $23.1 \%$, no tienen medidas suficientes el programa el 17.9\%, los costos de implementación son elevados el $12.3 \%$, otros el 20.4\%. (p. 10). Además, según INEI (2020) la percepción y motivación del empresario, respecto al tiempo en que recuperará su nivel de ventas, frente al covid-19; el 49.0\% indica que será mayor a 6 meses y menor a un año, el $15.7 \%$ indica que recuperará sus ventas de un año hasta 18 meses y el 17.8\% indica que superarán sus ventas después de 18 meses, solo el 17.5\% indica que la recuperación de ventas será menos de 6 meses (p. 11). Por último, INEI (2020) sobre la percepción de la reactivación económica, el 
$39.0 \%$ mayor a 6 meses hasta 1 año, el $36.1 \%$ mayor a un año hasta 2 años, el $15.2 \%$ son pesimistas mayores a 2 años, solo el 7.7\% indican que la economía peruana se recuperará en 6 meses (p. 12)

Según CCL (2020) conforme se minimiza la crisis sanitaria, con el objetivo de fortalecer al sector empresarial, el empleo y la recuperación económica de diversos sectores; la institución, propuso al gobierno, conformar una comisión para este escenario, con el papel de proponer medidas de auxilio a las empresas, una vez superada la pandemia covid-19, buscando, atenuar un posible crecimiento (rebrote) de esta pandemia covid-19; porque el estado de emergencia y el aislamiento social obligatorio; confirmado por evidencias científicas, desarrollarán secuelas en grupos etarios, que incidirá en el comportamiento en el hogar y familias, en el rendimiento laboral y estabilidad de empresas (p. 6). Para CCL (2020) "es primordial un marco legal que favorezca la continuidad de negocios, la recuperación de la demanda, a través de recomponer la cadena de pagos" (p. 7)

Para Reátegui (2020) los programas de reactivación como Reactiva Perú y FAE, han sido claves para mantener a flote a muchos microempresarios; para septiembre 2020, el Programa Reactiva Perú colocó 457,000 desembolsos, con garantías del Ministerio de Economía y Finanzas por un monto de 46,800 millones, donde hubo presencia de pequeñas y medianas empresas, validando la cobertura significativa por actividad y alcance geográfico; sin embargo, falta mucho que hacer en la informalidad creciente, que impide que puedan acceder a este rescate (p. 1). Además, Reátegui (2020) manifiesta que "después de un periodo de seis meses, se debe iniciar a supervisar los resultados obtenidos por el uso del dinero prestado a los beneficiarios, ante un contexto de caída de empleo e ingresos" (p. 2)

Además, existe retos pendientes, según lo manifestado por Reátegui (2020) aclara que es primordial "trabajar en el desarrollo de estrategias de desarrollo de mercado que permitan incorporar a más MIPYMES, en la política pública de apoyo financiero" (p. 2) significa, en el más breve plazo disminuir la informalidad, para que sean accesibles, bajo reforzar mecanismos de formalización; en donde estos, se sienten adversos como la declaración de impuestos, criterios de endeudamiento, licencias de funcionamiento, entre otros.

\subsection{Propuesta estratégicas externas e internas}

Vamos a divulgar una considerable cantidad de estrategias, propuestas por instituciones representativas, las cuales se analizan, discuten, aterrizando en una propuesta sintetizada:

Para Conexionesan (2020) manifestó que el 30\% de empresas peruanas ha tenido que cambiar de rubro a causa de la crisis sanitaria, para lograr el objetivo de conversión, implementaron estrategias de marketing para atender las nuevas necesidades de los consumidores y estrategias para reducir costos, lo cual trajo al inicio riesgos, pero se tomaron porque había la necesidad de sobrevivir (p. 1). Adicionalmente Conexionesan (2020) indicó que para alcanzar este objetivo tuvieron que aceptar, poner en práctica, el desarrollar una mayor habilidad de comprender sentimientos, pensamientos, necesidades de los consumidores, siendo estos más inestables; esto significó, tratar asegurar la mayor cantidad de clientes del segmento actual y ampliar hacia otros segmentos y resolver sus problemas; se suma la innovación, mediante el cambio en la propuesta de valor, la cual debe adaptarse a las nuevas necesidades de los consumidores (p. 2)

Según Sekulits y Fernández (2020) toman lo manifestado por Carlos Blanco; fundador de Nuclio Venture Builder, cuya posición expresa que "también es partidario de tomar medidas urgentes y asegura que, aunque impopulares, pueden salvar un negocio de la quiebra “(p. 1) esto se concreta mediante el análisis de que costos se deben evitar y de qué caja chica se dispone, esto debe planificarse de inmediato, además de ajustar los equipos al máximo. En ese sentido Sekulits et al (2020) toman lo expuesto por Pablo Ventura; socio de K. Fund, quien sugiere planes dinámicos, para enfrentar el comportamiento de la crisis, generando tres escenarios, corto-mediana recuperación, mediano-larga recuperación, largo-ajustes y transformación mayores, es necesario comprender el comportamiento del ritmo de contagios, y las medidas excepcionales del gobierno para salir de la crisis (p. 1). Prosiguen Sekulits et al (2020) especificando que será necesario 
congelar presupuestos de marketing, publicidad para convertirlos de preferencia a la web, además de proseguir recortando otros gastos imprescindibles, esto también nos hace cancelar contratos de suministradores externos que no sean imprescindibles, además del personal de planta (p. 2)

Además, respecto a proseguir con recortes de gastos y renegociación de compromisos pendientes, Sekulits et al (2020) exponen que las bajas sustanciales de ventas para los sectores afectados, ciclos de venta largos, aplazamiento de pagos, se debe reconvertir la forma de vender, aunque se conviertan temporalmente en menos eficientes, pero siempre eficaces, es decir el medio y recursos flexibilizar, pero siempre alcanzar un objetivo prudente, que permita al negocio sobrevivir y pasar la crisis; es imperioso maximizar caja (p. 2) . Asimismo, a partir de lo manifestado por Eneko Knörr; fundador de AngelClub.es, a diferencia de los anteriores, ciñen su recomendación en prever, en base a realizar un arqueo y fijar un colchón de dinero (efectivo) y otro dinero que sea rápido de convertir en efectivo, por consiguiente, es necesario que prevean todo tipo de escenario; de preferencia el más negativo, dado el comportamiento del avance de la propagación del virus Covid-19; es necesario pedir financiación lo antes posible, solo para operaciones de capital de trabajo imprescindibles; no se puede pedir financiamiento para incrementar acervo físico, deudas de equipamiento, entre otros (p. 2)

Complementan lo expuesto anteriormente, indicando que, al implementar estas acciones, los sectores que prevalecerán son salud, e-commerce, marketplaces, donde se practica el trabajo mixto y el teletrabajo, las corporaciones que no puedan adaptarse a los cambios de trabajo remoto o mixto; van estar afectadas económica y financiera (p. 2). Finalizando, apoyados en lo manifestado por Rodolfo Carpintier; presidente de la inversora $\mathrm{DaD}$, señala que lo primordial es reducir al máximo los gastos, además de conversar las posibilidades de financiamiento con inversores, bancos; es necesario exprimir el máximo de tesorería, sobre todo en la recuperación de las cobranzas, siendo en esta parte prudente, oportunos; de preferencia todo lo debemos hacer on line, es una oportunidad única para fortalecer y expandir las aplicaciones, que hasta ahora poco no se masificaba.

Los manifestado por Zelada (2020) indica que "El Covid-19 sirvió como instrumento de medición para conocer cuan preparados estábamos a nivel privado y público en la ruta de transformación digital” (p. 1). Se ha logró comprobar que todo tipo de organización ha tenido diferentes respuestas, buscando soluciones digitales e inclusive algunos el salto de la automatización; lo que se fortaleció con la implementación del trabajo remoto y mixto, generando confianza, seguridad, una mayor integridad hacia el personal; ello se centró en las fases siguientes:

- Tuvieron que responder, para mantener la continuidad del negocio, inician manejando la situación actual, aseguran la continuidad de las operaciones, ceñido a la tecnología y plataformas digitales, cuyo rol fue determinante.

- Tuvieron que recuperar, para aprender a surgir más fuerte, los líderes toman la iniciativa, ponerse frente del panorama, idear soluciones proactivas; aprovechar los aprendizajes de la crisis actual a partir de la implementación y desarrollo de estrategias, para soportar la crisis y sobreponerse sin mucha dificultad.

- Tuvieron que prosperar, para prepararse para la nueva normalidad, la pandemia, trajo la implementación forzada de tecnología y plataformas digitales, sin embargo, ello demuestra la capacidad de la empresa para cambiar la trayectoria, agregar valor, lograr que el negocio escale (p. 1)

Respecto a la posición y recomendación del Instituto Biosfhere-OMT (2020) la cual nos entrega una serie de recomendaciones estratégicas, que sirven para aprovechar el periodo que atravesamos, manifestando que "es una oportunidad para simular la amenaza y trabajar más con un enfoque de nuevo comienzo" (p. 1), presentamos una síntesis de la guía Call to action, para la reactivación del negocio. 
El instituto Biosfhere-OMT (2020) indica que la sostenibilidad económica, tienen como pilares la gestión global, el marketing y comunicación; lo cual significa mantener vivo los canales de comunicación, promoción institucionales haciendo seguimiento de las actuaciones y proyectos; elaborar un mapa de planificación estratégica donde se precise la gestión de ingresos y control de costos, tomando en cuenta tres escenarios de recuperación; rápida de 2 a 3 meses; media de 3 a 6 meses y lenta mayor a 6 meses (p. 9), sumado estrictamente a movilizar recursos humanos de acuerdo con las necesidades y posibilidades de simplificación de tarea, trabajo remoto o mixto (p. 10); adicionalmente, precisa que la sostenibilidad económica, se centra en asegurar soluciones fuera de caja chica, recibir apoyos como entrenamientos sobre su capacidad operativa, procedimientos de producción y servicios; integrar nuevos socios y negociar con clientes para una reprogramación en corto plazo, sobre la entrega de productos o servicios con servicios adicionales. Adiciona que se debe gestionar con proveedores la reducción de algunos costos y reprogramar compromisos de corto plazo en mutuo acuerdo; recuperar el negocio con mirada de diversificación, relanzamiento y mantener la marca del negocio en base a las alianzas de socios nuevos y renegociación con proveedores (pp. 12-14).

En ese sentido, la sostenibilidad sociocultural, es un eslabón primordial, porque tiene como pilares la gestión de personal, la actitud responsable y promover el desarrollo económico-social de la comunidad local; significa estrechar vínculos, relaciones con el personal apoyados de actividades en línea para mantener la comunicación; realizar reuniones para fortalecer el conocimiento y comunicación con empleados sobre el impacto de la crisis, escuchar las sugerencias de empleados y proveedores, para mejorar estrategias y procedimientos, asegurarnos que los trabajadores se encuentren bien de salud (pp. 21-22), de la misma forma, el instituto Biosfhere-OMT (2020) incide en que "es importante para los clientes, recibir información sobre el medio ambiente, los valores e identidad sociocultural del destino, además del papel de la empresa con el medio ambiente, mediante la entrega de directrices para un comportamiento responsable, además fortalecer la identificación de apoyo a la economía social “(p. 24).

Por lo cual , incide que la sostenibilidad ambiental, "es transversal, porque se basa en los pilares: entender y respetar la biodiversidad, la gestión eficiente de recursos frente a las emisiones atmosféricas; dentro de las acciones, se trata de desarrollar videos o documentales brindando información sobre el papel alcanzado por la empresa, respecto a su apoyo y respeto a los ecosistemas" (p. 26) y la aplicación de medidas para minimizar el uso de productos desechables y consumibles, sus intervenciones y pruebas para los clientes, mostrarles los procedimientos amigables con el medio ambiente, caso huella de carbono por el transporte público, que abraza la empresa (pp. 27-28), en esa dirección, el instituto Biosfhere-OMT (2020) manifiesta que "complementa a la sostenibilidad ambiental; la sostenibilidad sanitaria, cuyos pilares son: higiene, seguridad y salud; significa reforzar la cultura de prevención al contagio a partir de una mayor comunicación interna y externa con clientes y proveedores para adaptar el plan de higienización" (p. 30); además se debe establecer planes que contienen procedimientos de higiene de ambientes-fumigaciones-señalización durante la cuarentena, tener ambientes para aislamiento temporal o preventivo, realizar simulacros (pp. 31-32)

Para Valle (2021) las estrategias, pasos claves, para recuperar las empresas en la región Apurímac, donde predominan aquellas ligadas al sector turismo y comercio; dependerá solo y exclusivamente de la iniciativa privada; tendrán que diversificar su negocio, reaprender, adaptarlo, reorientarlo de tal forma que el levantamiento gradual del aislamiento y confinamiento social, permita la recuperación y reprogramación de actividades, sumado a una fuerte actividad de soporte tecnológico digital, aprovechando al máximo la web. Los servicios de seguridad, sanidad, protección, se complementan al acondicionamiento de la infraestructura, lo cual impulsa la promoción en redes sociales, ello permite captar otros mercados, cuyo rol digital les permite ingresar, ampliando oportunidades para sobrellevar esta crisis. El papel de los gremios de empresas, es complementario, porque permitirá coordinar políticas, acciones de intervención, defensa para las microempresas, en conjunto con el gobierno sub nacional en la región Apurímac; existe evidencia que los gremios todavía están en formación, son débiles, por el motivo que existe un poco cultura de cooperación desarrollada entre los miembros de los gremios, que por lo general, solo se juntan para exigir demandas 
respecto a derechos que le son denegados y que perjudican la operatividad del negocio o empresa familiar (pp. 104-105)

\section{MÉTODO Y DISEÑO DE INVESTIGACIÓN}

Según Hernández, Fernández y Baptista (2014) esta investigación está ubicada en el enfoque cualitativo, por las características de la variable de estudio. A partir de Carrasco (2005) es una investigación de tipo básica, que permite aportar conocimiento actual de la variable de estudio. Además, por Hernández et al. (2014) el diseño es no experimental, ligado al diseño estudio de caso, porque analiza a partir de la descripción los hechos y procesos, apoyados en la descripción detallada, analítica. Según (Fidias, 2012) las técnicas de investigación fueron: análisis de documentos; el instrumento de recojo de datos fue: lista de cotejo documentos.

Las unidades de análisis fueron los hechos que atravesaron las empresas producto de las medidas de prevención y aislamiento contra la propagación del Covid-19, detallados en fuentes secundarias. Las categorías de búsqueda fueron: Estrategia de negocio y crisis sanitaria Covid-19, la referencia bibliográfica se sostiene en archivos digitales, que fueron extraídos, consultados desde marzo a octubre 2020, que permitió cruzar información, siendo los portales web institucionales, siguientes: Instituto Nacional de Estadística e Informática, Ministerio de Comercio Exterior y Turismo, Ministerio de Trabajo y Promoción del Empleo, Ministerio de Salud, el Instituto Biosphere en alianza con la Organización Mundial de Turismo, Comisión Económica para América Latina y El Caribe (CEPAL).

\subsection{Procedimiento}

El procedimento, fue el siguiente: Revisión de literatura relacionada a los efectos, consecuencias en los negocios y/o empresas; que viene generando las estratégias implementadas por el gobierno de turno, sobre confinamento y aislamiento social, cuyo objetivo es frenar la propagación del vírus Covid-19, ocurrida durante los 10 últimos meses del año 2020, además de los diagnósticos de instituciones con competência en el sector empresarial. Se realizo la comparación y análisis, de la recomendación de estrategias por el Instituto Biosphere, la Organización Mundial de Turismo, el Ministerio de Comercio Exterior y Turismo, la Comisión Económica para América Latina y el Caribe, desde donde extraímos y selecionamos estrategias suficientes, cuyas recomendaciones eran próximas y se pueden implementar dado el contexto y realidad del sector empresarial peruano, además del estado que atraviesa la economia nacional y Latinoamericana; se prosiguió con el sustento estadístico especializado a través de informes del Instituto de Estadística e Informática, Ministerio de Salud, Ministerio de Trabajo y Promoción del Empleo. Se terminó con la construcción del contenido basado en las categorias: estratégia de negocio y crisis sanitária Covid-19.

\section{RESULTADO Y DISCUSIÓN}

\subsection{Resultado}

Es notoria la realidad que atraviesa el sector empresarial y la economia peruana, desde hace más de 10 años, se han creado programas de impulso para fortalecer los mecanismos para la formalización de negocios, la reducción de requisitos para incentivar, generar, condiciones de tal forma que los negocios asciendan hacia formas de organización superiores, desde una persona natural a una sociedad de responsabilidad limitada o hacia una sociedad anónima cerrada; según la legislación empresarial y tributaria en Perú.

Asimismo, a noviembre del 2020, se constituyeron mas de 78 mil empresas, de las cuales se dieron de baja mas de 5 mil; dentro de ellas las organizaciones jurídicas con mayor número de bajas fueron las personas naturales, que por lo general son microempresas, que alcanzó el 98.4\%, esto demuestra la situación grave, de negocios, cuya fuerza laboral no era mayor a 10 trabajadores y que dado su bajo nivel de tecnificación tecnológica, es muy difícil implementar al $100 \%$ el trabajo remoto, derivando en suspender trabajadores y mantener mínima fuerza laboral. 
Estas microempresas que presentaron mayor número de bajas, por lo general están ubicadas en los sectores: comercio al por menor con $34.8 \%$, comercio por mayor $16.0 \%$, servicios de comidas y bebidas el $7.8 \%$, siendo las mas representativas, que suman el 58.6\% del total, el cual sufrió un fuerte retroceso, como problemas financieros, reprogramación de contratos, renegociación con proveedores, flexibilizar compromisos pendientes; ajustar costos. Asimismo, las organizaciones jurídicas con mayor número de bajas son las personas naturales superando el $98.0 \%$.

Complementaron, con medidas laborales; una medida frecuente fue la flexibilización de horarios y la reducción de horas de trabajo, por lo general representan a empresas operativas en un promedio del 60\%; algunas gestiones fueron más agresivas, respecto a tomar decisiones para minimizar costos, adelantaron vacaciones de un considerable grupo de trabajadores, ligado además a la reducción de remuneraciones, en promedio alcanzó el $44 \%$ de las empresas; sin embargo, medidas más propicias a favor del personal como la entrega de un bono extra por trabajo presencial solo se generó a partir del $2.8 \%$ de empresas.

Las empresas operativas, manifestaron, que atravesaron por una serie de problemas para cumplir con sus compromisos financieros, además de otros diversos que existen, identificaron pasar al menos por un problema, que tuvieron que resolver, dentro de ellos podemos identificar, que el más frecuente y yuxtapuesto a otro fue la dificultad de cobrar las deudas de clientes y ello dificultó la cadena de pago para la adquisición de insumos, el pago a proveedores, en promedio alcanzó al 52\% de empresas. El otro escenario fue que el pago de las remuneraciones, fueron retrasadas, ello en acuerdo con los representantes de los trabajadores, dado el comportamiento de retrazo de recuperación del mercado y las restricciones del sistema financiero, las empresas afectadas fueron en promedio 39\%.

\subsection{Discusión}

Las estrategias que analizamos, están dirigidas para la realidad peruana, se tiene que tener en consideración, que, la economía peruana, el sector micro empresarial abarca por encima del $90 \%$ y de ello superior al 56\% están en situación de informalidad. Existen evidencias, específicamente a través de los Censos Nacionales de Población y Vivienda del Perú, en las secciones de recojo de datos sobre vivienda, dado el tipo de construcción no tiene una relación directa con su antecedente de financiamiento o sostén, lo frecuente es que se logra a partir de actividad comercial, teniendo restricción en la información respecto a la condición jurídica del negocio o empresa familiar, además no se tiene información respecto si la actividad comercial de personas naturales, están registradas, que por lo general se ubican en mercados de abastos, centros comerciales y locales propios.

Las estrategias, para recuperar las empresas en las diversas regiones del Perú, donde predominan aquellas ligadas al sector turismo, producción alimentaria y comercio; dependerá del tejido empresarial, al desarrollo productivo de diversos sectores, y quizás una posible industria; excluimos a lima porque es la metrópoli donde concentra el desarrollo de varias industrias; sin embargo existen otras regiones donde si hay un nivel de desarrollo industrial, como es el caso de Ancash, Trujillo, Arequipa, Ica, Piura, Lambayeque, Moquegua y Tacna; por lo general todas estas regiones presentan un desarrollo preliminar industrial, que ocupa entre el rango del 6\% a 10\% del Valor Agregado Bruto Regional.

En los gobiernos sub nacionales, donde se ubican empresas en sectores: comercial, turístico, agropecuario, extractivo y servicios gubernamentales, la microempresa se ciñe al negocio, llegando a elevarse a la categoría de empresa familiar, entonces en los negocios o empresas familiares, existe la contratación de mano de obra no calificada, jornalera, con inexistencia de beneficios, cuyo capital de inversión y trabajo es familiar, su categoría tributaria es persona natural por excelencia; bajo este contexto, la similitud de condiciones y formas de la microempresa a nivel Perú; la reactivación empresarial es exclusiva de la iniciativa privada. 
Por ello, las microempresas en Perú, para iniciar y fortalecer una sostenibilidad económica, deben cambiar la forma de dirigir, significa establecer un mapa de planificación estratégica, el cual contenga la dinámica de cómo se gestionará los ingresos y control de costos, para sobrevivir en el corto plazo y recuperarse en el mediano plazo. Es primordial que inicien una planificación dada la realidad que atraviesan, que nace a partir del escenario de crisis, para nuestro caso en Perú; el escenario más adecuado es una recuperación media de 3 a 6 meses y lenta mayor a 6 meses, debido a que la recuperación de la demanda va ser efímera, por el motivo del miedo y rechazo al contagio al Covid-19, el recurso humano, deberá ser asignado según las necesidades y posibilidades de simplificación de tarea, de preferencia para afianzar la seguridad y confianza del cliente interno, se prioriza el trabajo mixto con algunas labores específicas de presencia; esta readecuación de la simplificación de tarea, permitirá asegurar soluciones fuera de caja chica, consolida reprogramar y reentrenar al personal para ejecutar los procedimientos de producción y servicios; junto a gestionar con proveedores la reducción de algunos costos y reprogramar compromisos de corto plazo en mutuo acuerdo; recuperar el negocio con mirada de diversificación y relanzamiento.

Además, las condiciones estratégicas y acumulación de capital, van a permitir que racione el capital de trabajo, priorice la cancelación de deudas de corto plazo que no comprometan en negativo la producción de bienes o servicios, además con una negociación directa con trabajadores, se puede llegar a tomar acuerdos, para alargar un plazo prudente la cancelación de haberes a los trabajadores, de tal forma que permita un respiro o ayuda por parte del trabajador a la empresa, y no perder su cupo laboral.

Teniendo en consideración que, el sector empresarial peruano, lo conforman microempresas, encontramos dentro de ellos formas de acuerdos, tratos de trabajo que por lo general se ciñen a lo sociocultural; dado el diagnóstico podemos comprender que las medidas tomadas sobre tratar de reducir el personal al mínimo, adecuación de horarios de trabajo, simplificación de tareas, se implementa a partir de la coordinación con el personal y proveedores, se fortalece a partir de estrechar vínculos, una mayor relación con el personal apoyados de actividades en línea para mantener la comunicación, que permita minimizar los riesgos y compartir decisiones; es a partir de estas acciones implementadas que, el personal se siente cómodo al percibir, observar, cómo la administración establece medidas para proteger, mantener al personal, genera en ellos un compromiso, basado en una responsabilidad mayor por coadyuvar a recuperar el negocio, del cual ellos llevan el salario a sus hogares, aquí estamos fortaleciendo la sostenibilidad sociocultural,

Dado el avance de la pandemia Covid-19, las medidas de emergencia para prevenir el contagio establecidas por el gobierno peruano, deben ser tomadas por el sector micro empresarial como una oportunidad para corregir, modificar formas, costumbres de procesos operativos, la comercialización de productos o servicios que son ineficientes o en algunos casos obsoletos, que si se mantienen en la práctica organizacional, contribuirán a propagar el contagio del Covid-19, sin embargo, se tiene conocimiento que una prevención adecuada, bajo una readecuación de procesos de producción y comercialización de productos o servicios, no solo frena y evita contagio; sino que, las buenas prácticas de seguridad, higiene implementadas, contribuyen, sostienen la recuperación económica de la empresa.

Por ello se deben desarrollar las siguientes estrategias: minimizar el uso de productos desechables y consumibles; hacer seguimiento a la implementación de prácticas saludables al interior de la empresa respecto a políticas para evitar riesgos en el personal sobre la ergonomía y el tratamiento del estrés, en su lucha contra la pandemia Covid-19, demostrar a los clientes externos e internos los niveles controlados y prácticas de higiene, seguridad sobre contaminación cruzada y criterios para mejora de la salud; el avance en reforzar la cultura de prevención al contagio del Covid-19, mayor comunicación interna y externa con clientes y proveedores para adaptar el plan de higienización, sumado al contenido en los planes sobre los procedimientos de higiene de ambientes-fumigaciones-señalización durante la cuarentena. Los servicios de seguridad, sanidad, se complementan con acondicionamiento de la infraestructura, permite una mayor 
transitabilidad, disposición del uso de espacio para la ubicación de puntos de control-registro, lugares de reposo o descanso de clientes tanto externo e interno, puntos o lugar de aislamiento de prevención, esta evidencia específica en el negocio o empresa familiar, impulsa la promoción del cumplimiento de medidas sanitarias en redes sociales, permite captar otros mercados; todo esto fortalece la estrategia de sostenibilidad ambiental y sanitaria que se complementan y sostienen a la sostenibilidad económica.

\section{CONCLUSION}

La estrategia primordial que todo negocio debe implementar para sobrevivir, readaptarse, e iniciar una mejora, es planificar bajo dos escenarios posibles de recuperación: medio y lento; sostenido en el tejido empresarial y la contracción del contagio, rebrote del Covid-19, sumado a una fuerte actividad de soporte tecnológico digital, aprovechando al máximo la web. Las limitaciones en el negocio, por lo general se centran en una desconfianza, poco interés por invertir en tecnología y tomar riesgos financieros, las cuales pueden ser revertidas con medidas específicas, basadas en objetivos e indicadores de alcance progresivos, que permitirán acreditar la recuperación del negocio.

Sin embargo; ante la ampliación de las medidas de aislamiento y confinamiento social por parte del gobierno peruano, se deteriora fuerte la sostenibilidad económica, sociocultural, ambiental y sanitaria en el negocio, porque todas las actividades económicas, sobre todo las comerciales, turísticas, educativas, espectáculos, salud, financieras, que congrega mayor cantidad de personas, para construir y concluir las relaciones de negocios y/o transacciones económicas, están en quiebra.

Es imprescindible, diagnosticar caja chica, las cuentas por cobrar y compromisos con proveedores pendientes, renegociar las deudas de corto plazo ante la escasez de capital de trabajo, tomar decisión en la reducción de costos en áreas y procesos que no son imprescindibles, reorientar el gasto operativo hacia responder para mantener la continuidad del negocio, ceñido a la implementación de tecnología y plataformas digitales, que coadyuven hacia una mayor comunicación, coordinación para la implantación de estrategias y medidas ambientales sanitarias, imprescindibles para salvaguardar la salud y desempeño del personal, mantener a clientes bajo la demostración de la aplicación de buenas prácticas de higiene y prevención frente al Covid-19; esto permitirá diversificar su negocio y/o empresa familiar, aprovechando la oportunidad surgida por el levantamiento gradual del aislamiento y confinamiento social, basado en implementar condiciones estratégicas sobre cómo acumular capital, que permita sostener la sobrevivencia del negocio y/o empresa familiar.

Los negocios y/o empresas familiares, podrán surgir a partir de aprender e idear soluciones proactivas; aprovechar los aprendizajes de la crisis actual, que permita sobreponerse sin mucha dificultad, lo cual demuestra la capacidad de la empresa para cambiar la trayectoria, agregar valor, lograr que el negocio escale.

Las estrategias recomendadas, permiten implementarlas al contexto peruano; debido que la inversión en tecnología no es extrema, la reorganización de tareas, la adecuación de horarios de trabajo, la aprobación de estándares de desempeño bajo el contexto de la pandemia Covid-19; no ocasionan disfunciones en la organización, por el contrario, contribuyen a una mejor racionalización de recursos, ello permitirá que aquellos negocios y/o empresas familiares, resurjan.

Las futuras investigaciones, que se pueden desarrollar, se originan a partir de la toma de decisiones del propietario del negocio, al formular un plan estratégico e implementarlo, el desarrollo de las estrategias, basado en los objetivos, estándares e indicadores, permitirá demostrar que tipo de modelo de negocio basado en determinada estrategia, sesgado a un determinado escenario de recuperación, bajo el contexto pos Covid19, alcanzo resultados considerables. Además, contribuirá a investigaciones futuras, sobre la adecuación de la estrategia de manejo de recursos humanos, reorientación de procesos productivos, optimización del financiamiento y administración del capital de trabajo. 


\section{REFERENCIAS}

Biosfhere-OMT. (2020). Propuesta de acción para la recuperación empresarial del sector Turístico. Guía Call to actionBiosfhere, pp. 1-32. Recuperado de:

https://www.biospheretourism.com/assets/arxius/a313d6131c429da4c4c41ee0025a6494.pdf.

Cámara de Comercio de Lima (2020). Propuestas contra el covid-19. La cámara Comercio de Lima. Recuperado de: https://www.camaralima.org.pe/repositorioaps/0/0/par/edicion922/la_camara\%20922_final.pdf

Carrasco, D. (2007). Metodología de la investigación científica: pautas metodológicas para diseñar y elaborar el proyecto de investigación. Editorial San Marcos. Recuperado de: https://isbn.cloud/9789972383441/metodologia-de-la-investigacion-cientifical.

Comisión Económica para América Latina (2020). Sectores y empresas frente al Covid-19: emergencia y reactivación. Informe especial $N^{\circ} 4$, pp. 1-6. Recuperado de: https://www.cepal.org/es/publicaciones/45734-sectoresempresas-frente-al-covid-19-emergencia-reactivacion

Conexionesan (2020). Impacto de los planes de financiamiento en las PYMES durante la pandemia. Apuntes empresariales, pp. 1-3. Recuperado de: https://www.esan.edu.pe/apuntes-empresariales/2020/11/comoreinventarse-en-la-nueva-normalidad-y-no-morir-en-el-intento/.

El Peruano. (2020). Apuntalando a las mypes. Recuperado de: https://elperuano.pe/noticia-apuntalando-a-mypes95072.aspx?fbclid=IwAR2JO6ER6eMZtpNP5zpmPkSQCv7CHVSZwgx4yWBzPmN24yLpzR-mE49PUEE

Hernández, S. R, Fernández, C. C. \& Baptista, L.P. (2014). Metodología de la investigación. Mc Graw Hill. Recuperado de: https://www.uca.ac.cr/wp-content/uploads/2017/10/Investigacion.pdf.

Fidias, G. A. (2012). El Proyecto de Investigación. Editorial Episteme. Recuperado de: https://issuu.com/fidiasgerardoarias/docs/fidias_g._arias._el_proyecto_de_inv.

Instituto Nacional de Estadística e Informática (2020) Encuesta de opinión sobre el impacto del Covid-19 en las empresas. INEI. Recuperado de: https://www.inei.gob.pe/media/MenuRecursivo/boletines/resultados-encuestacovid-lima metropolitana-2020.pdf.

Ministerio de Economía y Finanzas (2021) Programa FAE. MEF. Recuperado de: https://www.mef.gob.pe/planeconomicocovid19/mype.html.

Ministerio de Economía y Finanzas (2021) Medidas tributarias. MEF. Recuperado de: https://www.mef.gob.pe/planeconomicocovid19/mype.html.

Ministerio de Economía y Finanzas (2021) Programa Reactiva Perú. MEF. Recuperado de: https://www.mef.gob.pe/planeconomicocovid19/mype.html.

Instituto Nacional de Estadística e Informática (2020). Demografía empresairal al III trimestre 2020. Lima: INEI, pp. 1-14. Recuperado el 10 de enero 2021, de https://www.inei.gob.pe/media/MenuRecursivo/boletines/boletindemografia_empresarial.pdf

Reátegui Vela, Walther (2020). Impacto de los planes de financiamiento en las PYMES durante la pandemia. Conexionesan, pp. 1-4. Recuperado de: https://www.esan.edu.pe/conexion/actualidad/2020/09/18/impacto-delos-planes-de-financiamiento-en-las-pymes-durante-la-pandemia/.

Sekulits, C \& Fernández, T (2020) Estrategias para superar la crisis del coronavirus. Gestión: expansión, pp. 1-3. Recuperado de: https://www.expansion.com/expansion-empleo/2020/03/23/5e74e1c7e5fdeaad1e8b45d8.html.

Valle D., Felipe R, (2021) Cuellos de botella que impiden la reactivación del sector turismo en la región Apurímac, Perú. Revista Delectus, Vol. 4 (1) 93-106, doi: 10.36996/delectus.

Zelada, Sandra (2020) Covid-19, un acelerador de la transformación digital. Amchamnews, pp. 1-2. Recuperado de: https://amcham.org.pe/ne-ws/covid-19-un-acelerador-de-la-transformacion-digital/. 